\title{
Retraction
}

\section{Retracted: Successful Treatment of Refractory Wart with a Topical Activated Vitamin D in a Renal Transplant Recipient}

\author{
Case Reports in Transplantation \\ Received 21 January 2022; Accepted 21 January 2022; Published 23 February 2022 \\ Copyright (C) 2022 Case Reports in Transplantation. This is an open access article distributed under the Creative Commons \\ Attribution License, which permits unrestricted use, distribution, and reproduction in any medium, provided the original work \\ is properly cited.
}

Case Reports in Transplantation has retracted the article titled "Successful Treatment of Refractory Wart with a Topical Activated Vitamin D in a Renal Transplant Recipient" [1], because it contains a duplicated figure with an article published in Journal of Dermatology [2]. It was identified that Figure 1 in [1] appears to be identical to Figure 3 in [2], despite differences in the description of the figures.

The authors were contacted for clarification, but they did not respond. The article is therefore retracted from the journal with the agreement of the Editorial Board due to concerns regarding the reliability of the data.

\section{References}

[1] L. Moscarelli, F. Annunziata, A. Mjeshtri et al., "Successful Treatment of Refractory Wart with a Topical Activated Vitamin D in a Renal Transplant Recipient," Case Reports in Transplantation, vol. 2011, Article ID 368623, 3 pages, 2011.

[2] I. Imagawa and H. Suzuki, "Successful treatment of refractory warts with topical vitamin $\mathrm{D}_{3}$ derivative (maxacalcitol, $1 \alpha, 25$ dihydroxy-22-oxacalcitriol) in 17 patients," Journal of Dermatology, vol. 34, no. 4, pp. 264-266, 2007. 